\title{
Oral health-related quality of life in patients with X-linked hypophosphatemia: a qualitative exploration
}

\author{
Caroline Nguyen ${ }^{1}$, Elisabeth Celestin ${ }^{2}$, Delphine Chambolle ${ }^{3}$, Agnès Linglart ${ }^{2,4,5,6}$, Martin Biosse Duplan ${ }^{1,7,8,9}$, \\ Catherine Chaussain ${ }^{1,7,8,10}$ and Lisa Friedlander (1) 1,11,12,13 \\ 'Université de Paris, FHU DDS-Net, Dental School, Paris, France \\ ${ }^{2}$ Filière OSCAR, Paris, France \\ ${ }^{3}$ Association of People with Vitamin-Resistant Hypophosphatemic Rickets, Suresnes, France \\ ${ }^{4}$ Paris Saclay University, AP-HP, DMU SEA, Endocrinology and Diabetes for Children, Le Kremlin Bicêtre, France \\ ${ }^{5}$ Reference Center for Rare Disorders of the Calcium and Phosphate Metabolism, Le Kremlin Bicêtre, France \\ ${ }^{6}$ Filière OSCAR and Platform of Expertise for Rare Diseases Paris-Saclay, Bicêtre Paris-Saclay Hospital, INSERM-U1185, Le Kremlin Bicêtre, France \\ ${ }^{7} \mathrm{APHP}$-Center for Rare Diseases of Calcium and Phosphate Metabolism, Paris, France \\ ${ }^{8}$ Hôpital Bretonneau, Service de Médecine Bucco-Dentaire, GH Nord Université de Paris, Paris, France \\ Université de Paris, Inserm U1163, Institute Imagine, Paris, France \\ ${ }^{10}$ Université de Paris, URP2496, Paris, France \\ ${ }^{11}$ Université de Paris Laboratoire ECEVE INSERM, UMR1123, Hôpital Robert Debré, Paris, France \\ ${ }^{12}$ Centre de Reference, Maladies Orales et Dentaires Rares, Hôpital Rothschild, APHP, Paris, France \\ ${ }^{13}$ Filière de Santé Maladies Rares TETECOU, Malformations Rares de la tête, du cou et des dents, Hôpital Necker, Paris, France
}

Correspondence should be addressed to L Friedlander: lisa.friedlander@inserm.fr

\begin{abstract}
Introduction: X-linked hypophosphatemia (XLH) is a rare, hereditary, and lifelong phosphate-wasting disorder characterized by rickets in childhood and impaired teeth mineralization. In the oral cavity, spontaneous abscesses can often occur without any clinical signs of alteration of the causal tooth. The objective of our study was to evaluate the oral care pathway and the oral health-related quality of life (OHRQoL) of patients following in an expert oral medicine department located within a Parisian hospital and working in close collaboration with an endocrinology department expert in this pathology.

Methods: This study employed a qualitative descriptive design including semi-structured interviews using guiding themes.

Results: Twenty-one patients were included in the study. The topics brought up exceeded the initial objectives as the patients mostly addressed the alteration of their oral health-related and general quality of life; a very chaotic oral health care pathway with oral health professionals not aware of their pathology; consequences on their social, professional, and school integration. Patients declared the importance of having a multidisciplinary team around them, including medical and dental professionals. Conclusions: The variety of manifestations in patients with XLH necessitates high coordination of multidisciplinary patient care to optimize quality of life and reduce disease burden. Oral health care pathways are very chaotic for patients who have difficulty in finding professionals with sufficient knowledge of the disease. OHRQoL is therefore diminished. This situation improves when patients enter a coordinated care network.
\end{abstract}
Key Words
- X-linked hypophosphatemia
- rare disease
oral health-related quality of life
- care pathways

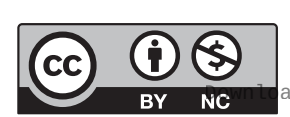

This work is licensed under a Creative Commons Attribution-NonCommercial 4.0 International License. ded from Bioscientifica.com at 04/26/2023 09:56:35AM
Endocrine Connections (2022) 11, e210564 


\section{Introduction}

In the European Union, a disease is considered rare when it affects fewer than one person in 2000 (1). Awareness of rare diseases has increased in the European Union since 2009 when the Council of the European Union asked the Member States to develop plans and strategies on this topic. $\mathrm{X}$-linked hypophosphatemia (XLH) is a rare, hereditary, progressive, and lifelong phosphate-wasting disorder characterized by pathological elevations in fibroblast growth factor (FGF) 23 concentration and activity with an X-linked dominant mode of transmission; XLH has an incidence of approximately 1 in 20-25,000 individuals. The gene responsible has been identified as the phosphateregulating endopeptidase homolog X-linked, which plays an important role in preserving phosphate balance in the body $(2,3)$. Excess FGF23 activity leads to increased phosphate excretion through the kidneys - mediated by downregulation of renal tubular phosphate transporters and reduced phosphate absorption in the intestines due to impaired vitamin D activation (4). Signs of XLH typically manifest in the first 2 years of life when bowed legs become apparent with the onset of weight-bearing. Other signs/ symptoms include impaired growth, bone tenderness, muscle weakness, spontaneous dental abscesses, muscle spasms, and wrist widening. Adults with XLH may develop additional complications such as hearing loss, hyperparathyroidism, obesity, nephrocalcinosis, kidney stones, periodontitis, osteoarthritis, and enthesopathy (2). In children and adults, recurrent dental abscesses or facial cellulitis of dental origin on a tooth of normal external appearance occurs. Patients may also present with craniostenosis. In adults, there is a poor oral condition with numerous devitalized teeth (especially those of the mandibular incisor and canine teeth, moderate to severe periodontitis, or several asymptomatic periapical lesions on teeth that have already been treated endodontically or not). The dental panoramic also shows large pulp chambers, devitalized teeth, generalized alveolysis, and/ or bone lacunae extending to several teeth. Treatment in a specialized center allows patients to be cared for by practitioners who are familiar with the pathology even when the clinical signs are complex to understand. Patients come to this center after having seen practitioners who do not know the disease and do not understand, for example, the fact that abscesses can occur spontaneously on visibly 'healthy' teeth. The dental manifestations of patients with XLH appear as soon as the teeth erupt and will persist throughout their lives resulting in severe functional, aesthetic, and nutritional problems $(5,6)$.
In France, management of patients with XLH (XLH rickets) is coordinated by an expertise center for calcium and phosphate metabolism, located at the Bicêtre Paris Saclay Hospital in Kremlin-Bicêtre, in the Paris suburbs. Dental care and follow-ups are carried out at the Bretonneau Hospital (Paris). The expertise center belongs to the OSCAR national network of healthcare providers for rare diseases of bone, calcium, and cartilage. A national diagnosis and care guideline protocol was set up by the expertise center in $2018(5,7)$.

It is challenging for XLH patients to manage many aspects of care that the disease necessitates. The rarity of the disease makes it difficult for patients to have access to high-quality oral care. Not only are few competent professionals known for the management of this disease but also professionals who are not trained in the phenotypic specificity of this disease may steer patients in therapeutic directions with poor outcomes. Furthermore, they can create additional barriers to a good quality of life due to insufficient access to information, treatment, and support, as well as the high stigma that the disease carries (8).

Many rare diseases have severe direct or indirect consequences on tooth formation (number, shape, structure anomalies) or craniofacial bone (9). However, in the case of XLH, these abnormalities are not secondary effects of the condition but a direct consequence of XLH on the tooth structure.

The objective of this study was to evaluate qualitatively the oral care pathways and oral health-related quality of life (OHRQoL) of patients with XLH.

\section{Methods}

\section{Design}

This study employed a qualitative descriptive design including semi-structured interviews using guiding themes.

\section{Participants}

This study includes children and adults to assess the impact of the disease on their daily lives with all possible nuances. Given the active file of patients with this pathology in the department studied, it was agreed to recruit around ten children and ten adult patients over a 6-month period until the data were thematically saturated. In collaboration with the medical team, the study participants were selected using the purposive

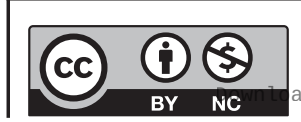

This work is licensed under a Creative Commons Attribution-NonCommercial 4.0 International License. ded from Bioscientifica.com at 04/26/2023 09:56:35AM 
sampling method. They were all under follow-up care in the above-mentioned center and had complete documentation. At the beginning of the planned care consultation, the practitioner and the researcher briefly but clearly explained the study and collected the nonopposition of the person taking part in the research or that of his legal representative (Table 1).

\section{Ethics approval and consent to participate}

The study was approved by the committee for the protection of individuals 'Ile de France 2'. Ethical and scientific approval were gained according to this local committee (CPP 2020-A02631-38) for the conduct of qualitative study involving patient interviews. Informed, written consent was gained and recorded. Data were handled in accordance to national data regulation guidelines.

\section{Consent for publication}

All the patients or their parents gave written informed consent for participation in the study and the publication of the study results.

\section{Eligibility criteria}

Eligibility criteria were to have XLH and to be a patient of the center aged over 6 years.

Table 1 Participant's characteristics.

\begin{tabular}{l}
\hline Participant \\
\hline Participant 1 \\
Participant 2 \\
Participant 3 \\
Participant 4 \\
Participant 5 \\
Participant 6 \\
Participant 7 \\
Participant 8 \\
Participant 9 \\
Participant 10 \\
Participant 11 \\
Participant 12 \\
Participant 13 \\
Participant 14 \\
Participant 15 \\
Participant 16 \\
Participant 17 \\
Participant 18 \\
Participant 19 \\
Participant 20 \\
Participant 21 \\
Mean age \\
Median age
\end{tabular}

\begin{tabular}{|c|c|c|}
\hline Gender & Age (years) & Occupation \\
\hline $\mathrm{F}$ & 61 & Invalid \\
\hline $\mathrm{F}$ & 10 & School \\
\hline $\mathrm{F}$ & 15 & School \\
\hline $\mathrm{F}$ & 51 & Medical secretary \\
\hline $\mathrm{F}$ & 39 & Administrative agent \\
\hline $\mathrm{F}$ & 29 & Assistant \\
\hline $\mathrm{F}$ & 18 & School \\
\hline $\mathrm{F}$ & 53 & Invalid \\
\hline $\mathrm{F}$ & 9 & School \\
\hline M & 19 & Unemployed \\
\hline $\mathrm{F}$ & 37 & Military \\
\hline $\mathrm{F}$ & 9 & School \\
\hline $\mathrm{F}$ & 18 & School \\
\hline $\mathrm{F}$ & 11 & School \\
\hline $\mathrm{F}$ & 36 & Employed \\
\hline $\mathrm{F}$ & 52 & Employed \\
\hline $\mathrm{F}$ & 11 & School \\
\hline M & 47 & Nurse \\
\hline $\mathrm{F}$ & 9 & School \\
\hline $\mathrm{F}$ & 48 & Academic \\
\hline \multirow[t]{3}{*}{ M } & 14 & School \\
\hline & 28 & \\
\hline & 23 & \\
\hline
\end{tabular}

\section{Procedure}

A semi-structured interview guide was developed by the research group and discussed with researchers and clinicians in our department beforehand.

\section{Interview}

\section{Data collection}

Face-to-face, semi-structured interviews were held by the first and second author (L.F. and C.N.), trained in qualitative sociological and anthropological interview methods. All interviews took place in the Dental Medicine Department of the Bretonneau Hospital in a dedicated room after a standard dental consultation. We used an interview guide, structured by the following six themes: 'care course', 'quality of life', 'feelings', 'impact of handicap disabilities', 'school and work integration and daily life', and 'renouncement to dental care'. During these interviews, themes were discussed with the patients who were encouraged to talk freely about their care pathway and their quality of life as well as their experiences and the repercussions on daily life.

Interviews with duration between 30 and 60 min were conducted and recorded in the period of October 2020 until March 2021. Transcripts and other sensitive data were stored at Research Clinical Unit in Robert Debré Hospital, Paris.

\section{Qualitative Thematic Analysis}

For the analysis of the qualitative data, the recorded interviews were manually transcribed and then analyzed using a thematic data analysis software (NVIVO 10 on Windows). The thematic analysis of the questionnaires was carried out according to the following process (10):

1. Key themes, or big ideas, were identified by reading and re-reading the interview transcripts.

2. Phrases or blocks of words that correspond directly to the research question were highlighted.

3. These phrases were categorized so that they can be grouped together thematically.

4. These categories gave rise to subthemes that were examined and analyzed.

The transcripts were reviewed to identify key themes and coded by a single researcher. Interviews were performed until the data were saturated and no further themes

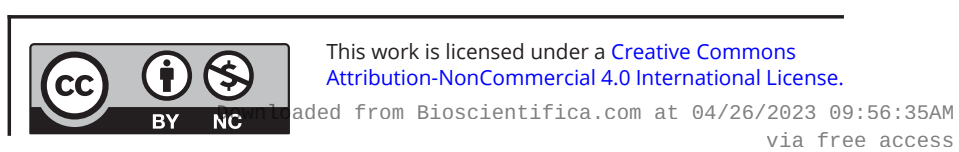


emerged, as is the current standard for qualitative data analysis in health settings.

Ten percent of the interviews were analyzed by a second coder to ensure consistency and quality assurance of the data.

Key themes were organized in a table and those mentioned by three or more patients were considered common.

Key common themes were converted into questions and grouped into general themes.

\section{Data credibility and rigor}

Data credibility was established through a triangulation strategy, which uses a combination of specialized teams to review and evaluate the results. In addition to semistructured interviews, data credibility was ensured by note taking during the interviews. Data were verified by both peers outside the study and by team members. The main findings were presented to some of the participants and their opinions were collected. In addition, the results were evaluated and verified on several occasions by supervisors. A review of the literature and data from other studies helped to improve the reliability of the results $(11,12)$.

\section{Results}

\section{The exploration of themes}

The different themes and subthemes discussed by the patients during the interviews are shown in Table 2 with the number of references per theme and the number of interviews in which the theme was present and in Table 3 with examples of patients' verbatim per theme and subthemes.

\section{Care course}

\section{Oral health care course}

Many patients describe a lack of awareness among dentists regarding the clinical signs of the condition. At the oral level, the care pathway is therefore felt to be very chaotic, with a lot of therapeutic delay.

The patients interviewed describe the challenge of finding competent local professionals acquainted with the disease. In most adults, this led to a worsening of their condition due to a lack of appropriate care (authors' analysis). All of them acknowledge an improvement in their condition when they were treated in the dedicated dental service in Paris, where medical professionals understand this pathology. The patients described their

Table 2 Themes and subthemes and number of references per theme.

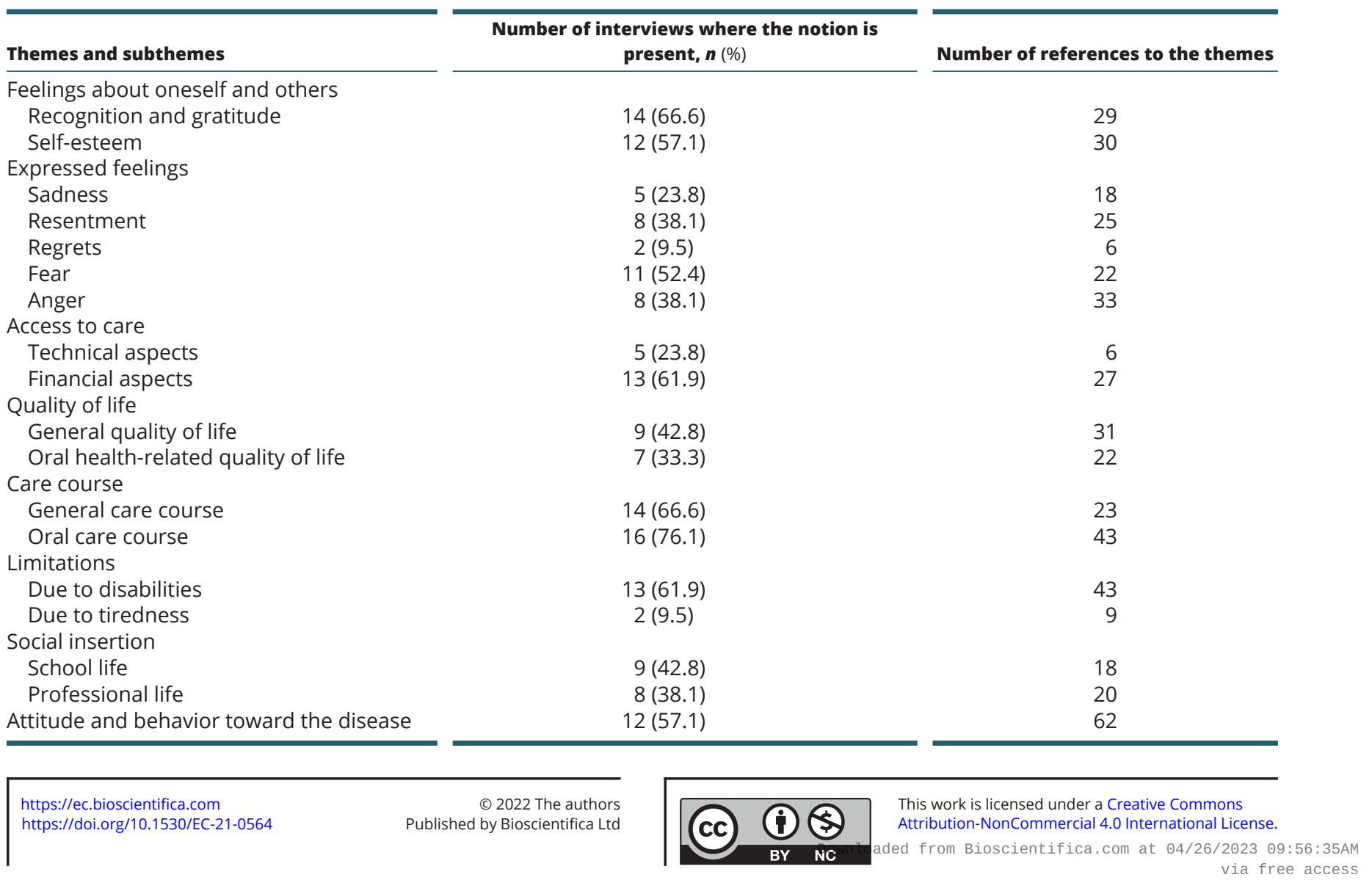


Table 3 Examples of extracted codes, subcategories, and categories.

$\begin{array}{ll}\text { Themes } & \text { Subthemes } \\ \begin{array}{c}\text { Expressed } \\ \text { feelings }\end{array} & \text { Sadness }\end{array}$

Resentment

Regrets

Fear

Anger

Access to care Financial aspects

Technical aspects

Quality of life

Oral health-related quality of life

\section{Quotations}

"I could no longer do my passion because I used to dance a lot, I could no longer dance'. (female, 61 years old, invalid)

'It affects life, the quality of life, not to mention the moral suffering'. (female, 52 years old, employed)

'I cry but ... well it's fine, it's over but it's still painful and it's a real choice ... it has an impact on psychological suffering, physically, we're not in a wheelchair, physically, we're normal, it still has an impact on daily life'. (male, 47 years old, nurse)

'When you are outside in a wheelchair ... when you see France behind on the problems, the pavements, the doors that have to be pulled up! You can't go to the toilet because it's not provided. Now they are obliged in the new structures'. (female, 61 years old, invalid)

'You need to get a haircut; how do you do it? You take your hair and then you put a bowl on your head and then you cut what's sticking out. I swear you have to see it to believe it'. (female,

61 years old, invalid)

'Where I work, in a research center, there are many areas where I could work, but the situation means that the qualifications are lower. And then, with secretarial diplomas, what do you do with that? You don't do anything'. (male, 47 years old, nurse)

'Afterwards, yes, I think I could have done more, been less of a failure than I was and done studies that would have taken me further maybe ... but it's sure that if I had been less absent in secondary school and high school...'. (female, 51 years old, medical secretary)

'I would have been perhaps less lost, less drowned in school'. (female, 51 years old, medical secretary) 'It's more afterwards, as I'm getting older, that I say to myself that maybe I should have been more careful, and now I'm careful about my son'. (female, 53 years old, invalid)

'I'm worried that I'm losing all my teeth, they're dying as I go along...'. (female, 37 years old, military) 'I'm worried that the implants won't work, and I'll have a total brace. And then I'm afraid I'll have hip replacements soon enough and then the pain I have is not getting better, on the contrary, it's getting worse. So, I'm not very optimistic about old age'. (male, 47 years old, nurse)

'What's really difficult is the transmission of the disease knowingly, like all genetic diseases I think'. (female, 29 years old, assistant)

I'm afraid that as the years go by it will get worse, because right now I'm young, I'm a bit energetic but I'm afraid it will have consequences later on'. (female, 18 years old, school)

'They don't want to keep crippled people at work'. (female, 61 years old, invalid)

'You need a haircut; how do you do it? You take your hair and then you put a bowl on your head and then you cut what's sticking out. I swear you have to see it to believe it'. (female, 61 years old, invalid) 'To be less blindfolded and say, well, I've learned that $A+B=C$ and well, that will never make $D$, there will never be any brackets for a little C or I don't know what. But then, whether it's a dentist or a doctor, it's the same thing. You realize that it's books, books, books ... lawyer, article 1, article 2. It's impressive how dentists and doctors are trained not to be curious, not to learn anything other than what they've learned in books, I don't understand, maybe it's a trick or I don't know ... that's the biggest criteria I would say. But be curious, look elsewhere, listen to the patient'. (female, 52 years old, employed)

'I even have a certificate that I have a dentist who told me that I was not profitable for him and that he could not treat me'. (female, 52 years old, employed)

'But if you don't have a full wallet, nobody will treat you'. (female, 52 years old, employed)

'The dentists didn't believe me, X-rays, healthy teeth, healthy exteriors, no cavities... And no matter how hard I tried to explain to them that I had spontaneous dental necrosis. Once, I went to 15 dentists but uh... I couldn't work anymore; it's really disabling because you can't have a life anymore'. (female, 52 years old, employed)

'They don't want to hear, especially in my area, I think they are not specialized at all. And then, there is still a lack of information in my area and so they don't want to hear that rickets can be the cause of many oral problems'. (female, 29 years old, assistant)

'You can't eat croutons, you can't eat things that hurt because I have a lot of bones sticking out, I have exostoses everywhere'. (female, 61 years old, invalid)

'So, crunching on a sandwich, it's always been since I got my bridge in the 85s, you can't crunch on apples. There are things you can't do but that's okay'. (female, 48 years old, academic)

'I can't chew left and right anymore, I tried to take a piece of meat out and it was the tooth I took out'. (female, 53 years old, invalid)

'It prevents me from sleeping, it prevents me from eating well. Instead of painkillers, sometimes I drink alcohol to knock myself out, which makes me very tired, but at least I recover more quickly in the morning to go to work'. (female, 36 years old, employed)

'Since I have a black tooth, I avoid smiling too much, but we keep smiling anyway, that's life'. (female, 53 years old, invalid)

'It wasn't cavities, so ... it was a pain that came on suddenly ... it was abscesses, so there you go and obviously it came on a Saturday night at 2 o'clock'. (female, 36 years old, employed)

'It's not very aesthetic, it's always, in terms of seduction, it's true that it's not fabulous but, well, it's not just the smile'. (female, 39 years old, administrative agent)

(Continued)

https://ec.bioscientifica.com

https://doi.org/10.1530/EC-21-0564 (c) 2022 The authors Published by Bioscientifica Ltd

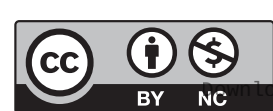

This work is licensed under a Creative Commons Attribution-NonCommercial 4.0 International License. ded from Bioscientifica,com at 04/26/2023 09:56:35AM 
Table 3 Continued.

Themes

\section{Subthemes}

General quality of life

Limitations

Due to disabilities

Social insertion Professional life

School life

Oral care course

General care course

https://doi.org/10.1530/EC-21-0564

\section{Quotations}

'There are many things in everyday life that make life difficult, and I use my electric wheelchair to do my shopping'. (female, 61 years old, invalid)

'And morally, I suffer enormously, I have a lot of physical pain, especially in my leg, sciatica, because it's the lumbar, and I would have to undergo an operation, but I don't want to because it has already weakened me so much in terms of walking'. (female, 61 years old, invalid)

'There was a time when I had to take all my treatment, all the time in front of others, I had to hide so that no one would ask me questions. No, I had a bad time of it, I had a really bad time of it'. (female, 36 years old, employed)

'With my wife, we decided not to have children, for example. Since it's a disease that is on the $X$ dominant gene and therefore, we have a one in two chance of having a sick child and I don't want a sick child'. (male, 47 years old, nurse)

'I had to get my ears fitted because, the disease affected my ears too'. (female, 61 years old, invalid)

'And even to cook, I can't do it because I can't stand up, because I walk with a walker at home, I have one downstairs and one upstairs, because walking with canes how do you want to hold a pan'.(male, 19, unemployed)

'It's a complicated time to be tired all the time and then, of course, the others don't understand, the mockery' (female, 37 years old, military)

'But it's a lot of suffering and a lot of fatigue. It's especially the fatigue of not sleeping for months on end. I have a tooth that needs to be treated, which has been treated, but it's still there'. (female, 52 years old, employed)

'Fatigue has affected my studies. It's affected my work, it's created a lot of work stoppages and brain fatigue which means that I'm really weakened intellectually some days, with a lowered morale'. (female, 52 years old, employed)

'the disease has affected my work; it creates a lot of downtime and brain fatigue, so I'm really weakened intellectually some days'. (female, 61 years old, invalid)

'I can't take a full-time job for example so ... it's complicated'. (female, 37 years old, military)

'You're a girl, you're disabled, you'll be a secretary, that's it. I did not have a choice. It wasn't what I wanted to do at all'. (female, 52 years old, employed)

'I was stopped after my hip replacement and ... they put me on disability and so now I realize that I couldn't really work at a job all day, it's becoming difficult'. (female, 39 years old, administrative agent)

'I often missed school and as the disease was not very well known until the age of... I knew my first class; I was nine years old'. (female, 52 years old, employed)

'It caused me to have absences, so I managed ... the school level it was but I found myself in a wheelchair regularly, I had to change schools. I was in a school where there was no lift. So, there was no wheelchair access, so I had to change schools. And then, I shut myself up in a shell'. (female, 11 years old, school)

'I had to redo my school year because I had a follow-up in the rehabilitation Centre, so I was a year late'. (female, 18 years old, school)

'They didn't understand why the gums recede, why my teeth die quite often ... we have to re-explain each time'.

'It's months and months of suffering, months of not believing, months of trying to explain a disease they didn't know about with supposedly healthy teeth'.

'The dentists didn't believe me... And no matter how much I explained to them that I had spontaneous dental necrosis PF. Once, I went to 15 dentists... I couldn't work anymore; it's really disabling because you can't have a life anymore'. (female, 61 years old, invalid)

'They started pulling my teeth and they realized that it wasn't a good principle and I... I've been to a lot of dentists in my life. Apart from offering me treatment or treating the cavity or ... they didn't understand. I could explain that I had a genetic disease, but dentists don't look at it like doctors do, they don't look at the disease at all'. (female, 36 years old, employed)

'My mother had taken me to all the hospitals, no one knew about the disease and so they said they had to come back when I was finished growing and operate on me'. (female, 11 years old, school)

'I was dragged from Lyon, Marseille, Paris, I went to a lot of places and they put me in a center, they spread my legs, they put me in plaster casts, they did a lot of tests. There was even a surgeon who wanted to remove my hips and put on plastic hips. It was all and then nothing. Everyone wanted to get my case to say, 'Yes, I discovered a case'. (female, 52 years old, employed)

'The doctor treating me doesn't know about this disease, in fact, there are many doctors ... it's a rare disease so they don't know about it'. (female, 11 years old, school) 
Table 3 Continued.

\begin{tabular}{lll}
\hline Themes & & Subthemes \\
\cline { 1 - 1 } $\begin{array}{l}\text { Feelings about } \\
\text { oneself and } \\
\text { others }\end{array}$ & & $\begin{array}{c}\text { Recognition and } \\
\text { gratitude }\end{array}$
\end{tabular}

\section{Quotations}

'Thanks to this doctor who defended my case in commission, and I was able to continue working'. (female, 53 years old, invalid)

'I am happy to be followed by a dentist who knows a little bit about pathology, and he is super careful, he doesn't hurt compared to other dentists, no, no... I prefer to take $1 \mathrm{~h}$ to come here and have a good dentist'. (female, 61 years old, invalid)

'The service is very good, we have the direct mobile numbers of the doctors, it's not everywhere. We're great, we're really lucky. And even, during the holidays, I needed to call because she had toothache, she made sure to find us a doctor, it's great, it's rare, we are really lucky to be here'. (female, 11 years old, school)

'Here I feel really listened to and above all, I am informed about the consequences of the disease and this allows me to adapt my lifestyle'. (female, 11 years old, school)

'Here I feel like I'm on another planet. I come here, they tell me about rickets normally, they tell me that there are solutions, they know what it can produce in my mouth and everything, I've never heard that. I don't feel like I'm crazy'. (female, 48 years old, academic)

Self-esteem

'I was always very self-conscious about my size so I was all dressed up when I went to work and anywhere else for that matter'. (female, 61 years old, invalid)

'If I don't have anyone coming to see me, I don't open my shutters all day, I cry, I just do it'. (male, 19 years old, unemployed)

'If you ask for someone to do your washing, then already psychologically it's very hard and well, everything goes with what'. (female, 37 years old, military)

'But before, I had to turn around to see if there was anyone behind me, so that no one could see how I was walking'. (female, 18-year-old school)

'Well, when I was at school, people didn't necessarily understand. So ... especially because you could see it because I had bowed legs, unlike my sister, you can't really see it, but I could really see it and I was teased'. (female, 18 years old. school)

Attitude and behavior toward the disease

'I never accepted the disease. Morally, it destroyed me'. (female, 61 years old, invalid) 'Morally, you are... I have never accepted the disease. Morally, it destroyed me'. (female, 61 years old, invalidity)

'But as I grew up, even before I had the operation, I understood that it's something you can't choose, and I grew up with it and I ended up accepting it on my own'. (male, 19 years old, unemployed) I've always loved humans, so l've never really had any... I've always loved humans, so l've never really hated them, but it's true that l've often put myself in the background to avoid talking and smiling stupidly when you know very well that things aren't going well, that all you want to do is go out the window'. (female, 37 years old, military)

'Teeth are a drag on your life. When you fight tooth pain, you can't fight it, because l've got two broken femoral necks, I've got fractured neck bones, you can't fight pain anywhere else and like dogs biting you everywhere'. (female, 52 years old, employed)

'I've always lived with pain, so I've dealt with it'. (male, 47 years old, nurse)

weariness with having to repeat the history of their disease and its oral particularities to all the dentists they had seen. They describe that dentists do not see the clinical link with the disease.

For children, parents describe that if they are taken care of early during childhood, it is much easier for them both.

The patients interviewed described multiple extractions, which they considered to be over-treatment, because, according to them, no one had been able to treat their teeth correctly until they arrived in the Parisian service.

The patients reproached the practitioners for not candidly saying when they did not know and for misdirecting them.

\section{General disease care course}

Some interview subjects described living far from the hospital. Adult patients and parents of young patients described challenges to care and diagnosis, going from doctor to doctor to get an accurate diagnosis.
One patient even described how a surgeon wanted to remove her hips and put plastic hips on her. Some patients described feeling like guinea pigs as children (authors' analysis).

Patients described that finding a team in a hospital department that could take care of their condition and direct them to this Parisian oral medicine department significantly improved their care pathway. Team cohesion and communication were a major source of improvement in their care pathway.

The patients interviewed described again, at times, a lack of knowledge of this rare disease on the part of general practitioners and doctors.

\section{Quality of life}

\section{General quality of life}

The interview subjects spoke at length about how the disease impacted their daily lives both psychologically

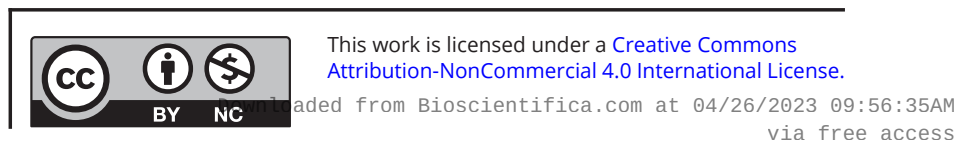


and physically. They reported a decrease in their physical abilities: leg pain of varying degrees in adults and children, including difficulty in walking, occurred during major physical efforts (long walks, runs, etc.). Patients refrained from playing certain sports they would have liked to play, such as football, or even taking part in physical education and sports classes at school, as they could not keep up. The patients described a general quality of life altered by the daily limitations due to the disability generated by the disease.

\section{Oral health-related quality of life}

The patients described episodes of intense pain, infection, an altered smile, problematic chewing, and even extracted teeth that were too expensive to replace. In terms of their oral health, quality of life became quite impaired (authors' analysis).

In terms of the function and appearance of their teeth, patients reported lifelong difficulties in eating, especially biting into bread or a sandwich. One of the main points described by the patients was the spontaneity and speed of infections, without prior signs. The patients mentioned that since their care was done in this specialized hospital service, constant attention was paid to both functional and aesthetic rehabilitation.

\section{Renouncement to oral health care}

\section{For financial reasons/aspects}

Whenever a patient described access to financial care in relation to oral rehabilitation, they described high fees, which were too expensive for them. Additionally, patients felt that practitioners expressed that they were not 'profitable' patients.

\section{For technical reasons/aspects}

In addition, as already mentioned, the patients interviewed described the ineptitude of many of the dentists they met in their care, unable to recognize the clinical features of their condition.

\section{Feelings expressed}

\section{Sadness}

The first feeling patients express is sadness arising from the diagnosis of an incurable progressive genetic disease. Many were diagnosed while young, sometimes without phenotypic expression, which created fear and apprehension regarding the future pathway of the disease.

The patients mentioned the moral and psychological suffering linked to the disease and the gradual onset of limitations in their daily performance. The psychological impact of the physical alteration, even for the patients interviewed who were not in a wheelchair, was widely reported.

\section{Fear}

Many patients expressed fear about the future, their own, and that of their children when they were also carriers of the pathology. This fear of the future focused on the deterioration of their physical conditions, on aging with significant joint pain, and an even greater deterioration of their oral health.

Their fear was also expressed in the slowness of the administrative processes to have their disability recognized.

\section{Resentment}

Furthermore, the patients interviewed expressed resentment against doctors who, in their opinion, had not been sufficiently attentive to their needs, even though they had a good reputation.

In addition, the patients interviewed have a lot of resentment and anger about the urban infrastructure, which they felt was not sufficiently adapted to physical disabilities and wheelchairs.

The patients' feelings of resentment and anger were quite focused on the lack of knowledge among professionals about their disease and the lack of accessible infrastructure.

\section{Feelings about oneself and others}

\section{Gratefulness}

When patients explained the difficulty of their oral health care pathway, they expressed gratitude toward the department where the interviews were conducted. Thanks to the expertise of the practitioners, they finally received appropriate care and were able to pose questions about the disease.

The availability and attentiveness of the practitioners were elements that were often mentioned by the patients interviewed.

The coordinated interdepartmental care provided by both dentists and rheumatologists ameliorated patients' symptoms and also improved their confidence in the medical system overall. 


\section{Self-esteem}

Patients reported many elements that echo their self-esteem. The disease has a huge impact on patients' growth and many report complexes about their height. These complexes also affect the description of the shape of their bowed legs.

The patients interviewed all described being teased at school as children. In addition, many of the patients' spoke of the inconvenience of taking their medication orally, which they had taken since childhood and which tasted bad, at different times of the day, particularly at school, where some had to hide to take it so that they would not be asked questions.

A loss of self-confidence, related to the disability generated by the disease, is also reported among the interview subjects. Furthermore, the patients interviewed reported that when, because of their disability, they needed help to do simple things such as their daily showering, the psychological impact was significant.

\section{Social integration}

\section{Professional integration}

The patients reported to professional worrying that they had been overlooked for promotions due to repeated absences for medical appointments or to physical disabilities. These same factors negatively affected their academic records at school.

\section{School Integration}

Young children reported their fears of bullying at school related to either their condition or their treatment. Many of the children interviewed said that they had to take their treatment in secret from others.

Patients described that school absences due to frequent medical appointments and procedures had a negative impact on their academic performance.

\section{Daily limitations}

The fact that they can no longer walk for long periods, dance, do housework, or drive, are elements that are often reported by the patients. In this respect, they mention the lack of accessible facilities, which excludes them from many activities, such as getting a haircut.

The patients also described that pain and physical discomfort are sources of impairment of their general quality of life. In this sense, the patients interviewed describe limitations in access to certain jobs and thus give up their professional careers.

\section{Attitude to disease}

Patients' perceptions of their disease and quality of life sometimes varied dramatically. Some patients were quite resigned and accepted the limitations in their daily lives on a day-to-day basis. Others were truly angry about the lack of facilities for people with disabilities, and their anger encompassed both their own limitations and their children's when they were also carriers of the same pathology. Among this latter group, patients expressed a feeling of guilt and of having transmitted the genetic disease. They expressed their relief to allow their children to receive an effective and adapted oral and general care pathway.

Overall, patients were more concerned about their general health than their oral health. Despite the feeling of being well followed in their care, patients were worried about the worsening of their symptoms, particularly their pain. Also, seeing the evolution of the disease in older people in their family was a source of concern but allowed them to realize that their care had changed for the better following an accurate diagnosis.

Regarding the future of their oral health, the main concerns of patients were the weakening of their teeth due to dental necrosis and that it may lead to edentulism. Similarly, the feeling of being well monitored and informed about the consequences of XLH on their oral health decreased the patients' worries: parents of XLH children were reassured to observe oral monitoring adapted to the oral conditions in their child.

\section{Discussion}

The present study was carried out to explore oral care pathways and OHRQoL based on patients' experiences. According to the WHO (2017), 'Oral health is essential for the overall condition and quality of not only the oral health-related quality of life but the general quality of life. It is characterized by the absence of oral or facial pain, oral or pharyngeal cancer, oral infection or injury, periodontal disease (gum disease), loosening and loss of teeth, and other diseases and disorders that limit a person's ability to bite, chew, smile, and speak, and thus their psychosocial well-being' (13). The notions of quality of life, in the field of health, and health-related quality of life are therefore often intimately linked, and it is sometimes complex in the words of patients to properly classify the concepts.

Results of the study revealed three main concepts including therapeutic delay for dental care, high daily-life

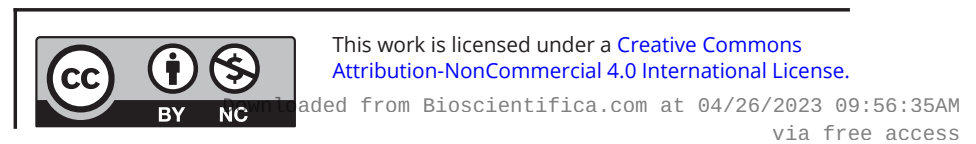


limitations, and strong gratitude and recognition toward the medical team of this expertise center for their knowledge of the disease. According to the study results, the first, and one of the most important problems that affects these patients' OHRQoL is the lack of knowledge among non-specialist dental surgeons about their pathology and therefore the delay of adapted management.

In the case of this disease, the oral care pathways are intricately linked to the general care pathway of the disease (14). The lack of knowledge by oral health professionals of the disease is a burden for patients (15). Therefore, in addition to the physical and dental pain, there is the frustration of not being listened to and understood. The pain, caused by abscesses and/or necrosis of the teeth, might have had no consequences - especially in children or it may have affected the patient's daily life: sleeplessness, physical suffering, and tiredness, as well as mental fatigue affecting their professional activity. Edentulism affected the patients' chewing ability; indeed, patients could not chew properly and had to avoid certain foods $(5,16)$.

Inappropriate management will necessarily have negative consequences on the patients' oral and general quality of life. These oral manifestations seem to be particularly unknown to private dentists who sometime refuse to manage patients due to lack of information and training.

The patients described, in a global and detailed way, their numerous difficulties before arriving to this specialized center, where the disease is very well known, to find suitable professionals who know the pathology. Most cases are diagnosed early in childhood, while some cases may be unrecognized until late in adulthood. Clinically, XLH is often misdiagnosed or missed altogether (8). This aspect of misdiagnosis is a major element, according to the patient's statements, in the alteration of their OHRQoL $(16,17)$. In a recent study concerning Credence to the Experience of XLH in adulthood, almost all participants reported more than one experience in which health care professional challenged their reported symptoms (e.g. bone pain) or questioned their diagnosis of XLH. Participants expressed concern about taking advice from providers who were not knowledgeable about XLH (18).

If the general, physical aspects of this pathology have been well described in the literature, this therapeutic delay for their oral health has been little described. One of the interests of this study is that it is carried out in a center of expertise working in close collaboration with rheumatology and endocrinology services specialized in this pathology (19). This transdisciplinary approach is one of the major keys to good patient care especially in case of rare diseases. All the patients interviewed described that their arrival in this department, with a multidisciplinary team working with practitioners dealing with their disease in all its manifestations, produces a large improvement in their care pathway and therefore their quality of life. Social and family aspects and therapeutic education must be an integral part of the care. The patient must be managed by a multidisciplinary team including an expert in metabolic bone pathology from the expertise center, a radiologist, an orthopedic surgeon, a rheumatologist, an endocrinologist, a physiotherapist, a neurosurgeon, a dentist, an orthodontist, a periodontal specialist, a psychologist, and a social worker (20).

It appeared to us that children appeared to be less impacted in their daily lives and their general and oral health care pathways than adults. We can explain this by several hypotheses. Children are now treated earlier, with a simpler and better-oriented care pathway than adults, often their parents themselves being ill. Treatments have evolved and are much earlier. In addition, it seems obvious that from an oral point of view, lesions and damages caused by the disease are less when the patients are children and that less care, often inappropriate, has been done on them. There is also, in the children we interviewed, a greater lightness and enthusiasm about their future life than adults.

As mentioned above, children are now treated earlier. The conventional treatment with $\mathrm{Pi}$ supplements and active vitamin $\mathrm{D}$ metabolites is prescribed to all children with XLH, as soon as the diagnosis is established (15). This therapeutic approach has shown positive outcomes on oral health $(7,21)$. More recently, a MAB targeting FGF23, Burosumab, has been introduced and has shown very positive outcomes on most of the manifestations associated to XLH (22). However, its long-term effects on oral health remain however to be evaluated (23).

The results of this study provide information not only on OHRQoL but also on the place of patients with disabilities in society, both in terms of professional integration and daily lives. During the interviews with the patients, many other themes were raised by both adults and children. Despite an interview guide that focused heavily on patients' oral health and oral health care pathways and their OHRQoL, we collected a lot of information and verbatim about patients' general health, life pathways, and overall quality of life. The richness of this type of study is that the information collected goes beyond the initial objectives. Even though the study focused on oral health care pathway, the patients were able to express themselves freely on the limitations due to

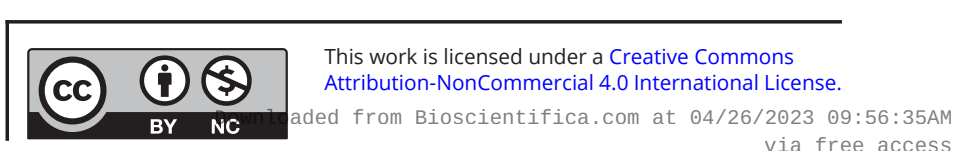


their disability, especially about their social integration, their relationship with others, and their place in society (18).

This is illustrated by what patients report in the study of daily limitations and pain due to the disease. The frustration of feeling the physical disability increase leading to the limitation of professional activities is well expressed by the patients. Home aides of patients in maintaining their autonomy and psychological support must be an essential component of the management of this disease (18).

\section{Limitations and strengths}

In this study, the patients have different disabilities even though they have the same pathology, and these disabilities limit them in varied ways. This initially may appear to impede the comparative basis of this study. In fact, neither we report different treatments taken by the patients nor did we quantify their body damage precisely. This was not the purpose of the study, and it does not seem to alter the interpretation of the results. Moreover, patients were interviewed in a department with a high level of expertise in this pathology. Patients therefore probably have a more severely affected oral health than other patients with the same pathology but in a less severe form. This pitfall was already expressed in a quality-of-life study in 2015, carried out in a center of the same network and this is why we cannot generalize these results to all patients with this pathology (2). Despite an interview guide that focused heavily on patients' oral health and oral health care pathways and their OHRQoL, we collected a lot of information and verbatim about patients' general health, life pathways, and overall quality of life.

Our study has clearly shown the complexity of the oral care course for patients with XLH, despite the establishment in recent years of a national rare diseases network and a political will, both French and European, to facilitate the care pathway for patients with rare diseases $(14,24,25)$.

\section{Conclusion}

Patients have largely reported the improvement of their care conditions since their arrival in this service where their pathology is very well known. Their oral care pathway has been very chaotic and has contributed as much to their poor OHRQoL as the disease itself.
Declaration of interest

The authors declare that there is no conflict of interest that could be perceived as prejudicing the impartiality of the research reported.

\section{Funding}

This work did not receive any specific grant from any funding agency in the public, commercial, or not-for-profit sector.

\section{Availability of data and materials}

The datasets during and/or analyzed during the current study are available from the corresponding author on a reasonable request.

\section{Author contribution statement}

All the authors were involved in the design of the study. M B D and C C treated the study patients and aided data collection. L F and $C \mathrm{~N}$ collected the data. L F and C N analyzed the data. C C supervised the results and conclusions. All the authors drafted the first and further versions of the manuscript. All the authors reviewed and revised the manuscript and approved its final version. Overall responsibility: L F.

\section{Acknowledgements}

The authors would like to thank all participants for taking part in the study and the clinical research team of the Robert Debré Hospital, in particular Mrs Sabrina Verchère.

\section{References}

1 PLAN NATIONAL Maladies RARES 2018-2022 Partager l'innovation, un diagnostic et un traitement pour chacun. (available at: https://so lidarites-sante.gouv.fr/IMG/pdf/pnmr_3_v25-09pdf.pdf)

2 Che H, Roux C, Etcheto A, Rothenbuhler A, Kamenicky P, Linglart A \& Briot K. Impaired quality of life in adults with X-linked hypophosphatemia and skeletal symptoms. European Journal of Endocrinology 2016 174 325-333. (https://doi.org/10.1530/EJE-15-0661)

3 X-linked hypophosphatemic rickets. (available at: https://www.rch sd.org/programs-services/nephrology/conditions-treated/X-linked-h ypophosphatemic-rickets/)

4 Padidela R, Nilsson O, Makitie O, Beck-Nielsen S, Ariceta G, Schnabel D, Brandi ML, Boot A, Levtchenko E, Smyth M, et al. The international X-linked hypophosphataemia (XLH) registry (NCT03193476): rationale for and description of an international, observational study. Orphanet Journal of Rare Diseases 202015172. (https://doi.org/10.1186/s13023-020-01434-4)

5 Linglart A, Biosse-Duplan M, Briot K, Chaussain C, Esterle L, Guillaume-Czitrom S, Kamenicky P, Nevoux J, Prié D, Rothenbuhler A, et al. Therapeutic management of hypophosphatemic rickets from infancy to adulthood. Endocrine Connections 20143 R13-R30. (https:// doi.org/10.1530/EC-13-0103)

6 Rabbani A, Rahmani P, Ziaee V \& Ghodoosi S. Dental problems in hypophosphatemic rickets, a cross sectional study. Iranian Journal of Pediatrics 201222 531-534.

7 Chaussain-Miller C, Sinding C, Wolikow M, Lasfargues JJ, Godeau G \& Garabédian M. Dental abnormalities in patients with familial hypophosphatemic vitamin D-resistant rickets: prevention by early treatment with 1-hydroxyvitamin D. Journal of Pediatrics 2003142 324-331. (https://doi.org/10.1067/mpd.2003.119)

8 Carpenter TO, Imel EA, Holm IA, Jan De Beur SM \& Insogna KL. A clinician's guide to X-linked hypophosphatemia. Journal of

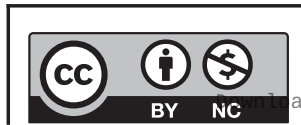
This work is licensed under a Creative Commons Attribution-NonCommercial 4.0 International License. ded from Bioscientifica.com at 04/26/2023 09:56:35AM 
Bone and Mineral Research 201126 1381-1388. (https://doi.org/ 10.1002/jbmr.340)

9 de La Dure-Molla M, Fournier BP, Manzanares MC, Acevedo AC, Hennekam RC, Friedlander L, Boy-Lefèvre ML, Kerner S, Toupenay S, Garrec P, et al. Elements of morphology: standard terminology for the teeth and classifying genetic dental disorders. American Journal of Medical Genetics, Part A 2019179 1913-1981. (https://doi.org/10.1002/ ajmg.a.61316)

10 View of theme in qualitative content analysis and thematic analysis | forum qualitative Sozialforschung/forum: qualitative social research. (available at: https://www.qualitative-research.net/index.php/fqs/arti cle/view/3376/4470)

11 Beck CT. Qualitative research: the evaluation of its credibility, fittingness, and auditability. Western Journal of Nursing Research 1993 15 263-266. (https://doi.org/10.1177/019394599301500212)

12 Lincoln YS. Emerging criteria for quality in qualitative and interpretive research. Qualitative Inquiry 19951 275-289. (https://doi. org/10.1177/107780049500100301)

13 Baiju RM, Peter E, Varghese NO \& Sivaram R. Oral health and quality of life: current concepts. Journal of Clinical and Diagnostic Research 2017 11 ZE21. (https://doi.org/10.7860/JCDR/2017/25866.10110)

14 Lo SH, Lachmann R, Williams A, Piglowska N \& Lloyd AJ. Exploring the burden of X-linked hypophosphatemia: a European multi-country qualitative study. Quality of Life Research 202029 1883-1893. (https:// doi.org/10.1007/s11136-020-02465-x)

15 Haffner D, Emma F, Eastwood DM, Duplan MB, Bacchetta J, Schnabel D, Wicart P, Bockenhauer D, Santos F, Levtchenko E, et al. Clinical practice recommendations for the diagnosis and management of X-linked hypophosphataemia. Nature Reviews: Nephrology 201915 435-455. (https://doi.org/10.1038/s41581-019-0152-5)

16 Hanisch M, Bohner L, Sabandal MMI, Kleinheinz J \& Jung S. Oral symptoms and oral health-related quality of life of individuals with X-linked hypophosphatemia. Head and Face Medicine 2019158. (https://doi.org/10.1186/s13005-019-0192-x)

17 Skrinar A, Dvorak-Ewell M, Evins A, Macica C, Linglart A, Imel EA, Theodore-Oklota C \& Martin JS. The lifelong impact of X-linked hypophosphatemia: results from a burden of disease survey. Journal of the Endocrine Society 20193 1321-1334. (https://doi.org/10.1210/ js.2018-00365)
18 Hughes M, Macica C, Meriano C \& Doyle M. Giving credence to the experience of $\mathrm{X}$-linked hypophosphatemia in adulthood: an interprofessional mixed-methods study. Journal of Patient-Centered Research and Reviews 20207 176-188. (https://doi.org/10.17294/23300698.1727)

19 Raimann A, Mindler GT, Kocijan R, Bekes K, Zwerina J, Haeusler G \& Ganger R. Multidisciplinary patient care in X-linked hypophosphatemic rickets: one challenge, many perspectives. Wiener Medizinische Wochenschrift 2020170 116-123. (https://doi.org/10.1007/ s10354-019-00732-2)

20 Lambert AS, Zhukouskaya V, Rothenbuhler A \& Linglart A. Diagnosis and care in X-linked hypophosphatemia. Revue $d u$ Rhumatisme Monographies 201986 55-63. (https://doi.org/10.1016/j. monrhu.2018.11.006)

21 Biosse Duplan M, Coyac BR, Bardet C, Zadikian C, Rothenbuhler A, Kamenicky P, Briot K, Linglart A \& Chaussain C. Phosphate and vitamin D prevent periodontitis in X-linked hypophosphatemia. Journal of Dental Research 201796 388-395. (https://doi. org/10.1177/0022034516677528)

22 Carpenter TO, Whyte MP, Imel EA, Boot AM, Högler W, Linglart A, Padidela R, van't Hoff W, Mao M, Chen CY, et al. Burosumab therapy in children with X-linked hypophosphatemia. New England Journal of Medicine 2018378 1987-1998. (https://doi.org/10.1056/ NEJMoa1714641)

23 Imel EA, Glorieux FH, Whyte MP, Munns CF, Ward LM, Nilsson O, Simmons JH, Padidela R, Namba N, Cheong HIl, et al. Burosumab versus conventional therapy in children with $\mathrm{X}$-linked hypophosphataemia: a randomised, active-controlled, open-label, phase 3 trial. Lancet 2019393 2416-2427. (https://doi.org/10.1016/ S0140-6736(19)30654-3)

24 Montserrat Moliner A \& Waligóra J. The European Union policy in the field of rare diseases. Public Health Genomics 2013 16 268-277. (https:// doi.org/10.1159/000355930)

25 Kodra Y, Weinbach J, Posada-de-la-Paz M, Coi A, Lemonnier SL, van Enckevort D, Roos M, Jacobsen A, Cornet R, Ahmed SF, et al. Recommendations for improving the quality of rare disease registries. International Journal of Environmental Research and Public Health 201815 1644. (https://doi.org/10.3390/ijerph 15081644)

Received in final form 8 December 2021

Accepted 22 December 2021

Accepted Manuscript published online 23 December 2021 (c) 2022 The authors Published by Bioscientifica Ltd
This work is licensed under a Creative Commons Attribution-NonCommercial 4.0 International License. ded from Bioscientifica.com at 04/26/2023 09:56:35AM 